\title{
A Política Nacional de Saúde Mental: uma reflexão acerca dos retrocessos nos governos Temer e Bolsonaro
}

\author{
The National Mental Health Policy: a reflection on the setbacks in the Temer and Bolsonaro \\ governments
}

\begin{abstract}
Berenice Lira da Silva* Alessandra Ximenes da Silva**

Resumo

Historicamente, uma série de mudanças tem ocorrido nos padrões de atenção à saúde mental no Brasil, por meio da Reforma Psiquiátrica (RP) e da Reforma Sanitária (RS), representando significativas conquistas para a sociedade civil. No entanto, apesar dos avanços, a mercantilização das políticas sociais tem prevalecido na conjuntura brasileira, dada a ofensiva neoliberal que a acompanha desde a década de 1990. Neste sentido, o presente artigo tem como objetivo discutir acerca das principais tendências da Política de Saúde Mental (PSM) brasileira, fazendo um recorte dos frequentes riscos de retrocessos empreendidos pelos governos Temer e Bolsonaro. Para tanto, o método de análise da realidade que pareceu pertinente para este estudo foi o crítico-dialético. Foi realizado uma revisão bibliográfica das principais categorias do estudo (Contrarreforma e Reforma Psiquiátrica) e uma pesquisa documental das principais legislações da PSM, com abordagem qualitativa. A discussão deste estudo aponta, portanto, que a PSM tem se desenvolvido na realidade brasileira, articulando avanço e conservadorismo, sobretudo a partir das propostas de tais governos, sob a ordem de um neoliberalismo ortodoxo, quando se verifica a volta de uma organização das forças restauradoras da saúde mental contra a RP.
\end{abstract}

Palavras-chave: Reforma Psiquiátrica. Saúde Mental. Rede de Atenção Psicossocial. Conservadorismo. Neoliberalismo Ortodoxo.

\begin{abstract}
Historically, a series of changes have occurred in the patterns of mental health care in Brazil, through the Psychiatric Reform (PR) and the Health Reform (HR), representing significant achievements for civil society. However, despite the advances, the commodification of social policies has prevailed in our context, given the neoliberal offensive that has been with us since the 1990s. In this sense, this article aims to discuss the main trends of the Brazilian Mental Health Policy (MHP), making a re-cut of the frequent risks of setbacks undertaken by the Temer and Bolsonaro governments. For that, the method of analysis of reality that seemed pertinent to us was the critical-dialectical. We carried out a bibliographic review of the main categories of the study - Counter-reform and Psychiatric Reform and a documentary research of the main laws of MHP, with a qualitative approach. Our discussion points out, therefore, that the MHP has developed in the Brazilian reality, articulating advancement and conservatism, especially from the proposals of such governments, under the order of an orthodox neoliberalism, when the restoration of an organization of restorative forces in mental health against PR occurs.
\end{abstract}

Keywords: Psychiatric Reform. Mental health. Psychosocial Care Network. Conservatism. Orthodox Neoliberalism.

\footnotetext{
* Mestranda em Serviço Social pela Universidade Estadual da Paraíba (UEPB); Bacharel em Serviço Social pela Universidade Estadual da Paraíba (UEPB).

** Doutora em Serviço Social pela Universidade Federal de Pernambuco. Docente do Departamento de Serviço Social da Universidade Estadual da Paraíba e da Pós- graduação em Serviço Social.
} 


\section{Introdução}

O presente artigo faz parte de uma pesquisa de Mestrado em Serviço Social, intitulada "A Rede de Atenção à Saúde Mental: um estudo acerca dos limites e possibilidades no município de Campina Grande - Paraíba".

A Reforma Psiquiátrica brasileira apresenta, dentre outras questões, novos direcionamentos aos padrões de atenção às pessoas com transtornos mentais, assim como às que sofrem com transtornos decorrentes do uso abusivo de álcool e outras drogas, por meio, por exemplo, da aprovação de normatizações que estabeleciam a substituição gradual dos leitos psiquiátricos por uma rede integrada de atenção à saúde mental. Dentre elas pode-se destacar a aprovação da Lei de no 10.216 de 6 de abril de 2001, também conhecida como Lei da Reforma Psiquiátrica, e a Portaria no 3.088 de 23 de dezembro de 2011, que institui a Rede de Atenção Psicossocial (RAPS), enquanto principal estratégia dentro da Política de Saúde Mental.

É importante ressaltar que as políticas de saúde e de saúde mental foram formuladas durante o processo de redemocratização. No entanto, a regulamentação e a implementação ocorrem na década de 1990, num contexto de debate sobre a necessidade da reforma do Estado brasileiro. Em resposta à crise mundial, há o avanço do neoliberalismo e as políticas sociais tendem à privatização, seletividade, focalização e descentralização.

Desde então, na política de saúde mental, "legislações e adoção de novas modalidades de atenção aos portadores de transtorno mental vêm sendo implantadas, tanto pela ação de agentes sociais como pelo Estado" (DIAS, 2007, p. 19), em um processo de construção permanente.

Apesar dos avanços, sabe-se que o processo de implementação do novo modelo de atenção psicossocial, da política de saúde mental e da Reforma Psiquiátrica brasileira em si tem se configurado em um movimento político-social historicamente marcado por desafios e contradições a serem superados, sobretudo na atualidade em que a tensão entre a sobrevivência do modelo psiquiátrico clássico e a proposta do modelo de atenção psicossocial territorial tem se mostrado cada vez mais presente. Faz parte de uma conjuntura, em que, a população brasileira, principalmente a classe trabalhadora, tem enfrentado "a maior ofensiva da história deste país contra o conjunto das conquistas civilizatórias de nosso Estado" (SOARES, 2018, p. 24). 
No que diz respeito à Política Nacional de Saúde Mental e à Política de Álcool e outras Drogas, foi vivenciado uma invasão de propostas conservadoras e que colocam em risco os direitos até aqui conquistados, sobretudo a partir dos governos Temer e Bolsonaro, sob a ordem de um neoliberalismo ortodoxo. Desse modo, o presente artigo tem como objetivo discutir acerca das principais tendências atuais da Política de Saúde Mental brasileira, fazendo um recorte dos frequentes riscos de retrocessos empreendidos por tais governos.

Para tanto, o método de análise da realidade que pareceu pertinente foi o críticodialético. Foi realizado ainda uma revisão bibliográfica das principais categorias do estudo (Contrarreforma e Reforma Psiquiátrica) e uma pesquisa documental com abordagem qualitativa sobre as principais legislações da Política de Saúde Mental: a Lei no 10.216 de 2001; a Portaria no 3.088 de 2011 a Resolução no 32 de 2017; a Portaria no 3.588 de 2017; e a Nota Técnica no 11 de 2019. Destarte, a seguir, discorreu-se sobre a abordagem sócio-histórica do processo de Reforma Psiquiátrica no Brasil, analisando as tendências atuais da PNSM, apontando os retrocessos nos governos Temer e Bolsonaro, e as considerações finais.

\section{Uma abordagem sócio-histórica do processo de Reforma Psiquiátrica no Brasil}

A Reforma Psiquiátrica foi inscrita numa conjuntura internacional de transformações pela superação da violência asilar (DELGADO et al., 2007), visto que os grandes hospitais psiquiátricos traziam consigo uma lógica de aprisionamento daquilo que não era socialmente aceito, constituindo um modelo de violência e exclusão, ou seja, a política de hospitalização da pessoa com transtorno mental, realizava uma assistência psiquiátrica com base em condutas de isolamento, vigilância e medicalização (SANDINI, 2002).

Em meados do século XX, tem início na Itália uma radical crítica e transformação do saber, do tratamento e das instituições psiquiátricas, enquanto os dois momentos anteriores limitaram-se a meras reformas do modelo psiquiátrico. Tais críticas foram impulsionadas principalmente pelo psiquiatra italiano Franco Basaglia, por meio da Antipsiquiatria (oriunda da Inglaterra) e da Psiquiatria Democrática Italiana, operando numa espécie de ruptura, com repercussões no mundo todo e de forma bem peculiar no Brasil.

Assim, surge na Itália o Movimento de Luta Antimanicomial, fortemente marcado pela ideia de defesa dos direitos humanos e de resgate da cidadania daquelas pessoas com transtornos mentais. Atrelado a essa luta, nasce o Movimento da Reforma Psiquiátrica, 
denunciando os manicômios como instituições de práticas violentas e propondo a construção de uma rede de estratégias territoriais e comunitárias (AMARANTE, 1998; BRASIL, 2008).

No Brasil, a partir da segunda metade dos anos de 1970, vivia-se um cenário de luta em prol da redemocratização política do país e da superação do regime ditatorial implantado em 1964; e de uma forte e prolongada crise econômica que se faz presente até os dias contemporâneos (BRAVO, 2009). Nessa conjuntura, os segmentos sociais colocam o modelo e as condições de saúde (implementados pelo regime) como pauta de suas mobilizações. Dentre os movimentos sociais presentes nesse processo, destaca-se o Movimento de Reforma Sanitária Brasileira (RSB), sujeito político e coletivo primordial na formulação do Projeto de Reforma Sanitária Brasileira.

Trata-se de um movimento contra hegemônico à ordem vigente, constituindo-se enquanto uma reforma social baseada em elementos como:

\footnotetext{
a) Democratização da saúde - em que se destaca a concepção ampliada de saúde, os determinantes sociais e o reconhecimento do direito público e universal à saúde; b) a democratização do Estado - com a ruptura com o modelo autocrático centralizador, respeitando o pacto federativo, a partir da descentralização das políticas com participação social via controle social e c) democratização da sociedade - com uma reforma intelectual e moral da sociedade, democratização da economia e da cultura etc. (COSTA, 2016, p. 88).
}

Uma vez promulgada a Constituição de 1988, fruto das lutas do movimento de RSB e também de outros movimentos sociais, o âmbito da saúde passa por um significativo avanço, visto que a saúde passa a ser reconhecida enquanto direito de todos e dever do Estado, evidenciando a sua condição essencial e sua relevância pública (SILVA, 2013).

É nesse contexto político, econômico e social, constituído de múltiplas determinações, que se deu, em 1990, a criação do Sistema Único de Saúde (SUS) regulamentado pela Lei de $n$ ㅇ 8.080/90, posteriormente complementada pela Lei $n$ ㅇ 8.142/90 -, considerada uma das primeiras mudanças em nível de Reforma Sanitária, baseada na concepção de seguridade social, firmada no tripé saúde, previdência e assistência social.

Paralelamente a esse processo de RSB, eclodiu a chamada Reforma Psiquiátrica, "a qual tem sua origem como movimento social no final dos anos de 1970, se organiza e se fortalece nos anos de 1980 e se transforma em política pública de saúde nos anos de 1990" (YASUI, 2006, p. 23). 
Logo, diante dessa configuração, as críticas ao modelo manicomial consolidado funcional ao regime autocrático burguês e consequentemente à manutenção do sistema - e as lutas das organizações de trabalhadores pelas reformulações das políticas de saúde mental no país começam a se fortalecer. O Movimento dos Trabalhadores em Saúde Mental (MTSM) - posteriormente transformado em Movimento Nacional da Luta Antimanicomial, com o lema "Por uma sociedade sem manicômios" - teve grande contribuição nisso e foi profundamente influenciado pelas experiências italiana, europeia e americana (AMARANTE, 1998).

Dentre os objetivos do MTSM, o autor Vasconcelos (2010) destaca a diminuição dos leitos em hospitais psiquiátricos e a não criação de novos; a regionalização da assistência psiquiátrica, a partir da oferta de novos serviços ambulatoriais em espaços geográficos de referência; o controle das internações e reinternações psiquiátricas no setor privado; a defesa da ampliação dos serviços ambulatoriais em saúde compostos por equipes multiprofissionais; além do processo de humanização dos hospitais e de reinserção social nos asilos estatais.

Também é válido ressaltar que, diante do contexto de luta pela democratização nacional em que esse processo se dá, no interior dos movimentos sociais de reforma psiquiátrica e luta antimanicomial, havia um claro entendimento de que a mudança da assistência psiquiátrica não seria um objetivo em si, mas estaria pautada também na busca por uma democracia plena e uma organização mais justa de sociedade, assim como ocorreu no campo da saúde ampliada, tendo em vista que o regime autocrático burguês já havia sinalizado a sua aliança com o manicômio em prol da manutenção do sistema (AMARANTE, 1998; COSTA, 2016).

O Ministério da Saúde define a Reforma Psiquiátrica como um processo:

[...] político e social complexo, composto de atores, instituições e forças de diferentes origens, e que incide em territórios diversos [...]. Compreendida como um conjunto de transformações de práticas, saberes, valores culturais e sociais, é no cotidiano da vida das instituições, dos serviços e das relações interpessoais que o processo da Reforma Psiquiátrica avança, marcado por impasses, tensões, conflitos e desafios (DELGADO et al., 2007, p. 39).

Em 12 de setembro de 1989, o Projeto de Lei no 3.657, construído pelo Movimento de Luta Antimanicomial junto com o Deputado Paulo Delgado (PT-MG) a partir das discussões gestadas na I Conferência Nacional de Saúde Mental, começa a tramitar no Congresso Nacional. O referido projeto propunha a regulamentação dos direitos do indivíduo com 
transtornos mentais e a extinção gradual dos manicômios no país, visando substituí-los por uma rede de atenção integrada à saúde mental (DELGADO et al., 2007).

Contudo, o referido PL passou doze anos tramitando no Congresso Nacional, fazendo parte de um jogo de interesses e negociações que visavam pôr em primeiro lugar a manutenção do modelo hospitalocêntrico psiquiátrico, próprio da onda conservadora com verniz neoliberal que se propagava no Brasil durante os anos de 1990, e com ela a reestruturação produtiva e a crise do marxismo (COSTA, 2016).

Após uma série de negociações e revisão de seu texto, o PL se concretizou, em 6 de abril de 2001, com a Lei de no 10.216 (conhecida como Lei da Reforma Psiquiátrica ou Lei Paulo Delgado), sendo considerada como um dos principais avanços na área de saúde mental, visto que foi a "primeira lei de desospitalização e desmanicomialização em discussão no parlamento latino-americano" (PEREIRA et al., 2006, p. 3), acarretando uma redução significativa em hospitais psiquiátricos, em sua maior parte privados.

No entanto, diante da conjuntura neoliberal em que se deu tal política, uma nova direção Ihe foi dada, ao passo que, em prol de avanços reais, o movimento acaba por abrir mão da sua proposta inicial de Reforma Psiquiátrica que falava da extinção dos hospitais psiquiátricos. A versão aprovada versa acerca da redução, objetivando a requalificação dos hospitais psiquiátricos, enquanto eles existam, não se contrapondo politicamente a eles (COSTA, 2016).

Com a promulgação dessa Lei, cuja organização é pensada a partir dos princípios do SUS: "universalidade, acessibilidade, controle social, participação social, integralidade, entre outros, seguindo as diretrizes da descentralização político-administrativa" (COSTA, 2016, p. 109) e a realização de Conferências Nacionais de Saúde Mental, estas enquanto dispositivos essenciais de participação e de controle social, a exemplo também da III Conferência Nacional de Saúde Mental, realizada em 2001, “a política de Saúde Mental do governo federal, alinhada com as diretrizes da Reforma Psiquiátrica, passa a consolidar-se, ganhando maior sustentação e visibilidade" (PEREIRA et al., 2006, p. 3).

Foi então, a partir desse processo que

Linhas específicas de financiamento são criadas pelo Ministério da Saúde para os serviços abertos e substitutivos ao hospital psiquiátrico e novos mecanismos são criados para a fiscalização, gestão e redução programada de leitos psiquiátricos no país. A partir deste ponto, a rede de atenção diária à saúde mental experimenta uma importante expansão, passando a alcançar regiões de grande tradição hospitalar, 
onde a assistência comunitária em saúde mental era praticamente inexistente. Neste mesmo período, o processo de desinstitucionalização de pessoas longamente internadas é impulsionado, com a criação do Programa "De Volta para Casa". Uma política de recursos humanos para a Reforma Psiquiátrica é construída, e é traçada a política para a questão do álcool e de outras drogas, incorporando a estratégia de redução de danos (BRASIL, 2005, p. 9).

Também como parte desse redirecionamento do modelo assistencial em saúde mental, o Ministério de Saúde, principalmente a partir dos Governos Lula, cria um arcabouço normativo para dar respaldo à ampliação da rede comunitária e ao controle dos hospitais psiquiátricos. Nesse conjunto destaca-se a Portaria/GM no 336, de 19 de fevereiro de 2002, e a Portaria no 130, de 26 de janeiro de 2012, que redefiniram os Centros de Atenção Psicossocial em relação à sua organização, ao porte e à especificidade da clientela atendida.

É válido ressaltar que anteriormente, mais precisamente em 1987, em São Paulo, foi implementada a primeira experiência de CAPS, antes de qualquer legislação oficial que pudesse regulamentar seu funcionamento, o chamado Centro de Atenção Psicossocial Prof. Luiz da Rocha Cerqueira. Logo, o surgimento do mesmo, segundo Amarante (1998, p. 82) “[...] passou a exercer forte influência na criação ou transformação de muitos serviços por todo o país".

A partir da redefinição proposta por tais portarias, passaram a existir: CAPS I, CAPS II, CAPS III, CAPSi (infantil ou infanto-juvenil), CAPSad (álcool e drogas) e CAPSad III (álcool e drogas), importantes dispositivos na organização de uma rede substitutiva ao Hospital Psiquiátrico, ao prestar atendimento clínico diário nos municípios.

Outro marco importante nesse processo ocorre em 2011, só após 10 anos da aprovação da Lei no 10.216/01, em que, por meio da Portaria no 3088/11, é instituída a Rede de Atenção Psicossocial que, no âmbito do SUS, prevê a ampliação e articulação de serviços constituídos até então, e ações de atenção psicossocial no país para pessoas com sofrimento ou transtornos mentais, inclusive aqueles decorrentes do uso prejudicial de drogas. Ou seja, como bem faz o alerta a autora Costa (2016, p. 119), os dispositivos já existiam, o que a portaria vem propor é a articulação das ações dos mesmos, mediação esta que é parte de "um processo vivo e muito mais complexo".

Segundo a referida portaria, a RAPS tem como objetivos gerais: 
de crack, álcool e outras drogas e suas famílias aos pontos de atenção; e III - garantir a articulação e integração dos pontos de atenção das redes de saúde no território, qualificando o cuidado por meio do acolhimento, do acompanhamento contínuo e da atenção às urgências (BRASIL, 2011).

Dentre os componentes da Rede de Atenção Psicossocial no território estão: a Atenção Básica em Saúde, que faz parte da Estratégia Saúde da Família, o Núcleo de Apoio à Saúde da Família, a Equipe de Consultório de Rua e a Equipe de apoio aos serviços do componente Atenção Residencial de Caráter transitório, e o Centro de Convivência e Cultura (GARCIA et al., 2013; BRASIL, 2011).

Tem-se ainda, a Atenção Psicossocial Estratégica, através dos Centros de Atenção Psicossocial (CAPS), em suas diferentes modalidades; Atenção de Urgência e Emergência; Atenção Residencial de Caráter Transitório; Atenção Hospitalar; a estratégia de desinstitucionalização, com serviços residenciais terapêuticos; e, por fim, a estratégia de Reabilitação Psicossocial (GARCIA et al., 2013; BRASIL, 2011).

É, pois, inegável que a RAPS, enquanto instrumento essencial para a consolidação da Reforma Psiquiátrica, tem se constituído em seu processo de concretização em meio a uma série de avanços significativos, mas, por outro lado, é perpassada por muitas limitações e contradições ao propor, por exemplo, a coexistência do hospital e a participação do setor privado e filantrópico por meio das Comunidades Terapêuticas como integrantes de uma Rede que tem como diretriz a Reforma Psiquiátrica.

Portanto, apesar dos visíveis avanços históricos alcançados com a Reforma Sanitária, a constituição do SUS e a Reforma Psiquiátrica, que possibilitaram significativos redirecionamentos no modelo de atenção à saúde e à saúde mental no Brasil, ainda há uma enorme distância entre o que propôs e o que de fato se efetivou, dado o contexto de contrarreforma do Estado que se iniciou na década de 1990 e se estende até os dias atuais, a influência das orientações neoliberais nas políticas sociais e o caráter de inovação e conservadorismo que estas possuem sob ordem do capital.

Desse modo, a política de saúde mental tem sido submetida a um cruel processo de sucateamento e precarização, sobretudo nos últimos anos, apontando para sérios riscos de retrocessos advindos da captação de fatias cada vez maiores do fundo público por parte do setor privado, como ver-se-á no próximo item. 


\section{Tendências atuais da Política de Saúde Mental: retrocessos nos governos Temer e Bolsonaro}

Ao mesclar avanço e conservadorismo, a política de saúde mental (e também a de saúde) tem se desenvolvido no Brasil, tendo em vista que o traço conservador próprio da história mostra o empenho das classes dominantes em impedir o processo de democratização da sociedade.

Destarte, diante do contexto de crise em que se movem as relações capitalistas, um conjunto de mudanças tem sido proposto à área de saúde mental, numa tentativa de conciliação em que predomina o modelo de reforma e humanização e a não ruptura com o modelo manicomial. Ou seja, o momento traz de volta a organização das forças restauradoras da saúde mental contra a Reforma Psiquiátrica, parte do processo de contrarreforma imposto às políticas sociais (COSTA, 2016; MOURA, 2017).

Nos últimos anos, em relação a tal retrocesso, destacam-se os governos do expresidente Michel Temer e do atual presidente Jair Messias Bolsonaro, sob a ordem de um neoliberalismo ortodoxo, considerando que "a economia se ajusta por meio de um equilíbrio natural e sendo assim intervenções estatais são desnecessárias" (SILVA; MISAILIDIS, 2016, p. 129). Portanto defendem a ideia de que a causa da crise está no excesso de gastos/demanda na economia, sobretudo o gasto público.

O neoliberalismo ortodoxo se constitui com o retorno das principais teses neoliberais, construídas mundialmente na década de 1970 e no Brasil na década de 1990. Tal corrente defende uma polícia econômica voltada para um duro ajuste fiscal, diminuição da intervenção estatal para as políticas sociais e privatização. No Brasil, a partir de 2016, esse ideário tem sido retomado através do aumento do autoritarismo e do conservadorismo do Estado, que tem feito uso da violência para impor à população suas amargas políticas.

Tal vertente se apresenta no contexto contemporâneo como a única alternativa para se enfrentar os efeitos da crise, resumindo-se à restrição da oferta monetária/creditícia e ao ajuste fiscal (CARCANHOLO, 2015), que se baseará, sobretudo, na redução dos gastos públicos, ou seja, "o ajuste à crise econômica será - e já está sendo - pago pela classe trabalhadora" (CARCANHOLO, 2015). 
Diante disso, na atual conformação, tem se observado uma significativa expansão dos riscos de retrocessos no que tange às conquistas sociais do conjunto da classe trabalhadora e da sociedade civil, dentre elas, aquelas empreendidas a partir da Reforma Psiquiátrica.

Tais retrocessos têm feito parte de um contexto em que o sistema capitalista se utiliza de um modelo privatizante da saúde mental como uma forma de acumulação, mais uma vez (ALVES; VELASQUE, 2013), ou seja, deixando evidente que o lucro da classe dominante sempre predomina sob qualquer política pública humana de qualidade.

Dentre os ataques direcionados à RP, no governo Temer, pode-se destacar a proposta de "revisão", leia-se desconfiguração, da Política Nacional de Saúde Mental por meio da Resolução no 32, lançada em 14 de dezembro de 2017 (e publicada no Diário Oficial da União em 22 de dezembro do mesmo ano), pelo gestor público federal responsável pela área, Dr. Quirino Cordeiro Júnior, em uma reunião da Comissão Intergestores Tripartite (CIT) em Brasília.

Para oficializar as medidas de desconfiguração da Rede de Atenção Psicossocial, houve a publicação da Portaria no 3.588 de 21 de dezembro de 2017, publicada sem nenhum tipo de debate público ampliado prévio, ferindo a legislação vigente, inclusive a Constituição Federal de 1988, que garante o controle social.

Em suma, o texto da Resolução no 32/2017 apresentado garante: a manutenção dos leitos em hospitais psiquiátricos, ao passo que veta fechamentos e expande valores pagos para a internação nessas instituições de $\mathrm{R} \$ 49$ para $\mathrm{R}$ \$ 80; estimula a criação de novas vagas em hospitais gerais; e propõe a ampliação das comunidades terapêuticas ligadas ao setor privado, de caráter religioso, para atender dependentes químicos por meio de um investimento bastante significativo, no valor que poderia chegar a R\$ 240 milhões por ano, contra quase $\mathrm{R} \$ 32$ milhões destinados por ano aos demais dispositivos que compõem a rede de atenção (BATALHA; DOMINGUEZ, 2018).

A Portaria no 3.588/2017, por sua vez, propõe um aumento do valor da diária de internação para aos hospitais psiquiátricos e amplia de $15 \%$ para $20 \%$ o número de leitos psiquiátricos nessas instituições. Também determina uma taxa de ocupação de $80 \%$ dos leitos de saúde mental nos hospitais gerais como condição para que recebam a verba de custeio do serviço, dentre outras medidas que representam juntas, segundo o representante do Conselho Nacional de Saúde, Ronald Ferreira, um sério retrocesso, ao passo que incentivam a cultura da hospitalização que possui uma clara lógica de segregação (SAMPAIO, 2018). 
Apesar do apoio, por exemplo, da Associação Brasileira de Psiquiatria, diversos especialistas e entidades ligadas à saúde coletiva acreditam que as mudanças pretendidas para a PNSM violam princípios da Reforma Psiquiátrica. Para a Associação Brasileira de Saúde Coletiva (Abrasco):

[...] o que está principalmente em questão é o retorno da ênfase dada a modalidades assistenciais conhecidas pela sua ineficácia nos processos de reabilitação psicossocial, reinserção social, singularização e autonomização de pessoas acometidas de transtornos mentais e de usuários de álcool e outras drogas, portanto, manicomializadoras (BATALHA; DOMINGUEZ, 2018, p. 24).

Dentre os principais pontos desse reordenamento na política de saúde mental que impactarão de forma significativa na lógica da PNSM, o Conselho Regional de Serviço Social do Rio Grande do Norte (CRESS/RN) (2017) elenca: a criação da rede de ambulatório de saúde mental, chamada de Assistência Multidisciplinar de Média Complexidade em Saúde Mental (AMent), prevista tanto na Resolução no 32/2017 quanto na Portaria no 3.588/2017, que seria um serviço intermediário entre CAPS e Atenção Básica.

Ainda segundo o CRESS/RN (2017), a criação desse serviço pode representar a quebra da "lógica de organização e estruturação dos serviços de saúde mental", visto que a Atenção Básica já ficou (ou pelo menos deveria estar) encarregada pelo atendimento às pessoas com transtornos psiquiátricos leves, e os CAPS foram encarregados pelo atendimento dos casos mais graves. Essa medida demonstra, portanto, a finalidade do governo de trazer de volta um modelo assistencial que segregou e desassistiu usuários(as).

O CRESS/RN (2017) e muitos outros especialistas contrários às medidas impostas destacam que a alteração da lógica de financiamento da PNSM acaba por estimular a ampliação dos hospitais psiquiátricos (que deveriam ser requisitados não como artifício de tratamento de rotina, mas como última necessidade, vale salientar), apesar de essa política abranger a criação de vagas em hospitais gerais, que é uma demanda legítima do Movimento da Luta Antimanicomial (mas que tem agora sua forma de financiamento alterada de mensal para verba por internação registrada). O que de fato aparenta é que há uma tendência em transferir a responsabilidade de execução aos setores do grande Capital "por meio da construção de novos conglomerados de hospitais e clínicas psiquiátricas" (CRESS/RN, 2017).

Ainda nessa linha de discussão acerca do modelo hospitalocêntrico, além da "nova PNSM" incluir, através da Resolução no 32/2017, o Hospital Psiquiátrico Especializado como dispositivo/componente da RAPS, o que também se pretende é que os recursos de leitos 
psiquiátricos que vierem a ser desocupados não serão mais destinados para os serviços substitutivos, pois tais leitos não serão mais fechados (como previa a Lei $n$ o $10.216 / 2001$ ) e sim ocupados por um outro possível paciente. Tais recursos, imprescindíveis para expansão e manutenção desses serviços, ficarão, portanto, congelados.

Desse modo, tal medida, mais uma vez, vai de encontro ao que determina a legislação anteriormente vigente, que aponta que se deve dar prioridade à expansão e qualificação da Rede de Atenção Psicossocial, que ainda se encontra em processo de consolidação, para que seja possível dar seguimento ao movimento de substituição dos leitos em hospitais psiquiátricos (CRESS/RN, 2017). Ou seja, além de dar apoio a hospitais psiquiátricos, a proposta traz consigo a possibilidade de desfinanciamento de outros serviços, tendo como consequência o sucateamento da rede comunitária de saúde mental, já precarizada.

O debate incide também sobre outro ponto dessas mudanças, que é a inclusão das comunidades terapêuticas (regulamentada pelo governo Dilma em 2015) no rol de componentes da Rede de Atenção Psicossocial, conforme previsto na Resolução no 32/2017 em seu artigo 11.

1

Ou seja, instituições que, em geral, são mantidas por grupos privados e entidades filantrópicas e que atualmente já recebam recursos do Ministério da Justiça como apoio à acolhida de usuários de álcool e outras drogas agora passarão a ser financiadas pelo Ministério da Saúde e oficialmente reconhecidas como equipamentos de saúde.

Para muitos especialistas isso representa, assim como a maioria das proposições presentes nessa "revisão" da política de saúde mental, um movimento de desqualificação total da RAPS, visto que haverá um robusto investimento na manutenção de instituições "baseadas no modelo asilar, que atuam a partir do isolamento de usuários(as) de álcool e drogas e da abstinência forçada" (CRP/SC, 2017).

Isto é, além desse redirecionamento da política ferir fortemente os princípios da Reforma Psiquiátrica que preveem a substituição do modelo asilar, de internação e exclusão social e criação de uma rede de serviços territoriais de atenção psicossocial, visa atender interesses puramente mercadológicos da "indústria da loucura", quando resolve favorecer ainda mais a iniciativa privada, transformando a saúde mental em um negócio.

\footnotetext{
1 Artigo que visa: "Fortalecer a parceria e o apoio intersetorial entre MS/MJ/MDS/MT em relação às Comunidades Terapêuticas".
} 
Logo, o processo de privatização se espalha por todos os setores estatais, e como parte desse processo encontram-se tais alterações, que para Ana Sandra Fernandes Nóbrega (vice-presidente do Conselho Federal de Psicologia e presidente da Comissão Intersetorial de Saúde Mental do Conselho Nacional de Saúde), embora tenha ocorrido o fechamento de mais de 60 mil leitos no Brasil por meio da Reforma Psiquiátrica, não houve uma abertura efetiva de um campo substitutivo com outras possibilidades de cuidado, dado a insuficiência de recursos e investimentos que poderiam ampliar os serviços de atenção psicossocial.

É nesse momento, portanto, que a rede privada se apropria da ausência do Estado, assim, donos de hospitais privados, por exemplo, desejam o retorno "do parque manicomial" custeado pelo SUS. Ou seja, o que se pretende é uma enorme rede de hospitais conveniados pagos pelo SUS, com o mínimo possível de regulação (EVANGELISTA, 2017).

O desmonte imposto à política de saúde mental continua na atual gestão do projeto político ultraconservador do presidente Jair Bolsonaro, que tem tomado medidas que assustadoramente apontam para a aceleração do processo de desmonte do Sistema Único de Saúde (SUS) e das políticas intersetoriais (Assistência Social e Educação, principalmente), sobretudo através da Emenda Constitucional no 95/2016, com impactos imediatos para as políticas públicas de saúde mental que vêm "andando em marcha ré ou ainda na contramão dos princípios que há 18 anos orientaram a Lei no 10.216 que instituiu a Reforma Psiquiátrica" (PERES, 2019, p. 23).

Uma das primeiras medidas do governo de ataque à área de saúde mental e as demandas da luta antimanicomial é a divulgação da Nota Técnica no 11/2019

2

que visa dar esclarecimentos sobre as mudanças na Política Nacional de Saúde Mental e nas Diretrizes da Política Nacional sobre Drogas. De acordo com o autor Delgado,

[...] além da crítica genérica sobre a "ideologia” presente na política de saúde mental (reproduzindo a retórica ideológica "anti-ideologia" do governo Bolsonaro), substituída por uma visão "científica", alguns pontos devem ser destacados, pois representam uma medida direta de desconstrução da reforma psiquiátrica: reforço do papel estratégico do hospital psiquiátrico; ênfase na internação de crianças e adolescentes; ênfase em métodos biológicos de tratamento, como a

\footnotetext{
2 Segundo Amarante (2019, p. 35), a “nota se intitula 'técnica' sob o argumento de que 'as abordagens e condutas devem ser baseadas em evidências científicas, atualizadas constantemente', mas tem como objetivo mascarar o fato de que é um documento de natureza exclusivamente política".
} 
eletroconvulsoterapia; disjunção entre a saúde mental e a política de álcool e outras drogas; e condenação das estratégias de redução de danos (DELGADO, 2019, p. 3).

Outro ponto que merece destaque é a criação de uma nova modalidade de CAPS AD, do tipo IV, já previsto na Portaria no 3.588/17 do governo Temer, mencionada anteriormente, que propõe que os mesmos funcionem 24 horas, sob a justificativa de uma suposta ampliação do atendimento, mas que, na verdade, na prática acaba por facilitar a internação compulsória de quem seja tido como usuário,

[...] abrindo precedentes para todo tipo de violação dos direitos - tanto dos dependentes como dos que possam ser convenientemente rotulados sob essa categoria para justificar sua internação involuntária. Não é à toa, a resolução diz que essas unidades serão abertas prioritariamente em regiões de "cracolândias" (ESQUERDA DIÁRIO, 2019).

Além disso, a política de álcool e outras drogas passa à gestão do superministério da Cidadania, que agrupa Desenvolvimento Social, Cultura e Esporte, cujo titular, proveniente do governo Temer, propaga uma clara política de apoio às comunidades terapêuticas, contra a estratégia de redução de danos e em defesa da abstinência como única possibilidade (DELGADO, 2019). A autora Peres $(2019$, p. 25$)$ afirma que, atualmente, "uma em cada quatro comunidades terapêuticas do país é financiada pelo governo federal. Em março, o Ministério da Cidadania assinou contratos com 496 delas - antes, esse número era de 280 -, para um repasse de $\mathrm{R} \$ 153,7$ milhões ao ano".

Desse modo, diversas entidades, conselhos e estudiosos da área se colocaram contrários à referida nota técnica, dentre eles, o Conselho Federal de Psicologia (2019), que repudiou veementemente o teor do documento, uma vez que, segundo Marisa Helena Alves (representante do Conselho Nacional de Saúde), dentre os diversos ataques impostos, a medida rompe com a política de desinstitucionalização, estimulando a hospitalização e o tratamento desumanizado.

Ainda segundo Marisa Helena, a reafirmação da inclusão dos hospitais psiquiátricos entre os mecanismos da RAPS aponta para uma grave desconstrução, já em curso, pois, ao se colocar o hospital no centro do cuidado em saúde mental, o sujeito tem a sua liberdade violada, dentro de um sistema que não favorece a recuperação, mas puramente o isolamento, fazendo com que o Brasil "volte" 30 anos atrás.

Sob o avanço da contrarreforma psiquiátrica, empreendida desde o governo de Michel Temer, essa nota representa 
[...] ataques frontais às lutas por direitos humanos, pela humanização do tratamento de pacientes de saúde mental, contra a lógica manicomial e diversas conquistas que foram fruto de décadas de luta de pacientes, profissionais da saúde, familiares e da população em geral, muitas das quais foram parcialmente consolidadas pela reforma psiquiátrica de 2001 (ESQUERDA DIÁRIO, 2019).

Tais medidas visam, portanto, ao fortalecimento de uma lógica autoritária, restritiva, que tem como centro o lucro e que tem o médico como detentor de um saber absoluto frente ao paciente, "com um poder e uma autoridade inquestionáveis, e que se fundamenta numa ciência cujos pressupostos epistemológicos e científicos são completamente falhos, dada sua submissão à lógica do capital” (ESQUERDA DIÁRIO, 2019). É válido ressaltar que, após uma série de polêmicas geradas em torno dos pontos abordados ao longo de suas 32 páginas, a nota foi retirada do site do Ministério da Saúde, o que não significa que esteja fora de discussão (PERES, 2019).

Outro ataque se deu com o Decreto Presidencial no 9.926/2019, publicado em 22 de julho, que excluiu as vagas destinadas a especialistas e integrantes da sociedade civil no Conselho Nacional de Políticas sobre Drogas, dentre eles estão juristas, psicólogos, assistentes sociais, médicos, conselhos especializados. No total, mais de 10 categorias deixaram de existir na nova composição do Conad, que é agora composto, em sua maior parte, por participantes pertencentes ao governo, como, por exemplo, os ministros Sérgio Moro (Justiça), Damares Alves (Mulher, Família e Direitos Humanos), Paulo Guedes (Economia), Abraham Weintraub (Educação) e Osmar Terra (Cidadania) (GALVANI, 2019).

De acordo com o Conselho Federal de Serviço Social (2019), esse decreto, de cunho também autoritário e antidemocrático, característica bem típica das medidas empreendidas pelo atual governo, representa mais um retrocesso na Política sobre Drogas brasileira,

[...] não só porque exclui a participação de quem mais está envolvido e lida com essas questões no cotidiano, que é a sociedade civil e especialistas no debate, mas também porque quer impor um modelo de combate ao uso de drogas violento e punitivo, que visa trancafiar o usuário em comunidades terapêuticas que, na maioria das vezes, se parecem com manicômios que violam direitos humanos fundamentais [...]. Impedir a participação do Serviço Social e de outras categorias profissionais da saúde dos debates do Conad é, sem dúvida alguma, uma tentativa de calar a opinião técnico-científica de profissionais que têm apontado caminhos alternativos para a questão das drogas no país (CFESS, 2019). 
Portanto, o cenário atual é marcado pelo crítico crescimento do conservadorismo no trato das políticas sociais e na sociedade brasileira como um todo, parte de uma conjuntura de retirada dos Direitos Econômicos, Sociais e Culturais do conjunto da classe trabalhadora, visando cumprir uma agenda política e econômica que serve à ofensiva neoliberal em sua face ortodoxa, abraçada integralmente pelo governo do ex-presidente Temer e pelo atual governo de extrema direita do presidente Bolsonaro.

\section{Considerações Finais}

O presente artigo suscitou a análise de como a política de saúde mental tem se constituído, dada uma conjuntura complexa em que a proposta neoliberal de contrarreforma do Estado, que consiste basicamente na redução do papel deste, tem trazido significativas implicações para as políticas sociais brasileiras (dentre elas a de saúde e a de saúde mental) ao longo dos anos, a partir dos processos de Reforma Sanitária e de Reforma Psiquiátrica.

Dentre os desdobramentos de tais reformas, está a política de saúde mental (regulamentada pela Lei $\mathrm{n}$ - 10.216/01), que tem como objetivo a proteção dos direitos das pessoas portadoras de transtornos mentais e/ou com problemas decorrentes do uso de álcool e outras drogas e o redirecionamento do modelo de assistência em saúde mental, através, por exemplo, da Rede de Atenção Psicossocial, substitutiva ao modelo manicomial excludente, regulamentada, por sua vez, pela Portaria no 3.088/11, propondo a ampliação e articulação de serviços e ações intersetoriais de atenção psicossocial para essas pessoas.

No entanto, pode-se compreender que, apesar dos avanços alcançados a partir das Reformas Sanitária e Psiquiátrica, no que diz respeito à "garantia de direitos, pautando-se numa concepção ampliada da saúde e pressupondo-se a participação efetiva da população no controle social" (SOUSA et al., 2017, p. 97), ainda há uma enorme distância entre o que ambas propõem e o que de fato se efetivou, isto é, estas ainda são conquistas a serem consolidadas, numa conjuntura de retrocessos e de incentivos à privatização, direta ou indireta (SOUSA et al., 2017), empreendidos pelo processo de contrarreforma do Estado neoliberal.

Desse modo, a discussão aponta que, ao mesclar avanço e conservadorismo, a política de saúde mental (e a política de saúde) tem se desenvolvido no cenário brasileiro, principalmente na atualidade, quando se constata a volta de uma organização das forças restauradoras da saúde mental contra a RP, a partir das propostas do ex-governo Temer e do atual governo Bolsonaro, sob a ordem de um neoliberalismo ortodoxo. 
Em suma, tais propostas apontam para uma total desqualificação da RAPS e da lógica da RP, por meio, por exemplo, da Resolução no 32/2017, de modo que a tendência é vivenciar um dos maiores retrocessos desde 1990, expresso não só na violação e descumprimento da Lei $\mathrm{n}$ - 10.216/01 e da Portaria no 3.088/11, mas dos princípios do próprio SUS e dos Direitos Humanos, ao se investir em serviços que não permitem a construção da autonomia de pessoas com transtornos psíquicos em detrimento dos serviços de base comunitária e de atenção psicossocial, corroborando com o rompimento da lógica de desinstitucionalização psiquiátrica, abrindo as portas para os interesses da "indústria da loucura".

Portanto, é importante que tenha-se clareza quanto à formatação de uma política de Estado que regula a RP e visa ao resgaste da cidadania das pessoas em sofrimento psíquico, de modo que fique claro ser necessário ir muito além do fechamento dos hospitais psiquiátricos e da implantação de novos dispositivos de atenção. É preciso propor mudanças na forma de conceber a realidade, logo, esse entendimento demanda de uma análise contínua das condições históricas e das determinações em que se efetiva sua operacionalização (COSTA, 2017).

Desse modo, este estudo pretende contribuir para o fortalecimento do processo de RP em suas variadas formas, uma vez que traz a público o debate de algumas problemáticas que têm se constituído para que esse fortalecimento se efetive, debate essencial para que se construam estratégias de lutas em prol de uma atenção à saúde e à saúde mental que sejam públicas, universais, de qualidade e que não privem a sociedade brasileira de seus direitos já garantidos constitucionalmente.

\section{Referências}

ALVES, V. C., VELASQUE, M. de A. Desafios para a efetivação das políticas de saúde e saúde mental no contexto neoliberal. In: Seminário Internacional sobre Políticas Públicas, Intersetorialidade e Família: Desafios éticos no ensino, na pesquisa e na formação profissional, 1., 2013, Porto Alegre. Anais... Porto Alegre: PUCRS, 2013. p. 1-10. Disponível em: http://ebooks.pucrs.br/edipucrs/anais/ sipinf/edicoes/l/17.pdf. Acesso em: 10 jun. 2019.

AMARANTE, P. D. de C. Loucos pela vida: a trajetória da reforma psiquiátrica no Brasil. 2. ed. Rio de Janeiro: Editora Fiocruz, 1998.

AMARANTE, P. D. de C. A ameaça "técnica" da indústria da loucura. Revista Radis, Rio de Janeiro: Editora Fiocruz, n. 198, p. 35, 2019. 
BATALHA, E.; DOMINGUEZ, B. Hospitais Psiquiátricos: nunca mais? Revista Radis, Rio de Janeiro: Editora Fiocruz, n. 184, p. 24, 2018.

BRASIL. Lei no 10.216, de 6 de abril de 2001. Dispõe sobre a proteção e os direitos das pessoas portadoras de transtornos mentais e redireciona o modelo assistencial em saúde mental. Brasília, 2001. Disponível em: http://www.planalto.gov.br/ccivil 03/LEIS/LEIS 2001/L10216.htm. Acesso em: 25 jun. 2019.

BRASIL. Ministério da Saúde. Mostra Fotográfica Programa De Volta para Casa: cartilha de monitoria. Brasília: Editora do Ministério da Saúde, 2008. Disponível em:

http://bvsms.saude.gov.br/bvs/publicacoes/mostra fotografica programa volta casa p1.p df. Acesso em: 15 jul. 2019.

BRASIL. Ministério da Saúde. Nota Técnica № 11/2019-CGMAD/DAPES/SAS/MS. Assunto: Esclarecimentos sobre as mudanças na Política Nacional de Saúde Mental e nas Diretrizes da Política Nacional sobre Drogas. Brasília, 4 fev. 2019.

BRASIL. Ministério da Saúde. Portaria 3.588, de 21 de dezembro de 2017. Altera as Portarias de Consolidação no 3 e no 6, de 28 de setembro de 2017, para dispor sobre a Rede de Atenção Psicossocial, e dá outras providências. Disponível em: $\underline{\text { http://bvsms }}$ .saude.gov.br/bvs/saudelegis/gm/2017/prt3588 2212 2017.html. Acesso em: 8 jul. 2019.

BRASIL. Ministério da Saúde. Portaria/GM no 130, de 26 de janeiro de 2012. Redefine o Centro de Atenção Psicossocial de Álcool e outras Drogas 24 h (CAPS AD III) e os respectivos incentivos financeiros. Brasília, 2012. Disponível em: http://bvsms.saude .gov.br/bvs/saudelegis/gm/2012/prt0130 2601 2012.html. Acesso em: 27 jun. 2019.

BRASIL. Ministério da Saúde. Portaria/GM no 3088, de 23 de dezembro de 2011. Institui a Rede de Atenção Psicossocial para pessoas com sofrimento ou transtorno mental e com necessidades decorrentes do uso de crack e outras drogas, no âmbito do Sistema Único de Saúde (SUS). Brasília, 2011. Disponível em: http://bvsms.saude.gov.br/ bvs/saudelegis/gm/2011/prt3088 23122011 rep.html. Acesso em: 27 jun. 2019.

BRASIL. Ministério da Saúde. Portaria/GM no 336, de 19 de fevereiro de 2002. Estabelecem os Centros de Atenção Psicossocial (CAPS) nas suas modalidades e normatiza suas possíveis ações. Disponível em: http://www.maringa.pr.gov.br/ cisam/portaria336.pdf. Acesso em: 26 jun. 2019.

BRASIL. Ministério da Saúde. Reforma psiquiátrica e política de saúde mental no Brasil. Documento apresentado à Conferência Regional de Reforma dos Serviços de Saúde Mental: 15 anos depois de Caracas. OPAS. Brasília, 2005. Disponível em: http:// bvsms.saude.gov.br/bvs/publicacoes/Relatorio15 anos Caracas.pdf. Acesso em: 15 jul. 2019.

BRASIL. Ministério da Saúde. Resolução no 32, de 14 de dezembro de 2017. Estabelece as Diretrizes para o Fortalecimento da Rede de Atenção Psicossocial (RAPS). Disponível em: 
http://www.lex.com.br/legis 27593248 resolucao n 32 de 14 de dezembro de 2017.aspx. Acesso em: 8 jul. 2019.

BRAVO, M. I. S. Política de Saúde no Brasil. In: MOTA, Ana Elizabete et al. (Org.). Serviço Social e Saúde: formação e trabalho profissional. São Paulo: Cortez; Brasília: OPAS, OMS, Ministério da Saúde, 2009.

CARCANHOLO, M. D. Neoliberalismo, Ortodoxia e Ajuste Econômico: crítica da economia política brasileira. Blog Marxismo 21. Dossiê Ajuste Fiscal. Publicado em: out. 2015. Disponível em: https://marxismo21.org/wp-content/uploads/2015/10/ MarceloCarcanholo.pdf. Acesso em: 10 maio 2020.

CONSELHO FEDERAL DE PSICOLOGIA (CFP). CFP manifesta repúdio à nota técnica "Nova Saúde Mental" publicada pelo Ministério da Saúde. Brasília, 8 fev. 2019. Disponível em: https://site.cfp.org.br/cfp-manifesta-repudio-a-nota-tecnica-nova-saude-mental-publicadapelo-ministerio-da-saude/?fbclid=IwAROvcm2-TNRegMJ CNeDeQCIDkyRyix9gxrPB7rQfHF0Gt79KwrhE-qMDbk. Acesso em: 30 jul. 2019.

CONSELHO FEDERAL DE SERVIÇO SOCIAL (CFESS). Nota de repúdio à retirada da participação popular do Conad. Brasília, 22 jul. 2019. Disponível em: http://www.cfess. org.br/visualizar/noticia/cod/1596?fbclid=IwAR08STDeZUKWiOO5jxgfuZS ybkKrm5uV5vSxy 9zALDsrAFBPTGzSTPI 11. Acesso em: 30 jul. 2019.

CONSELHO REGIONAL DE PSICOLOGIA DE SANTA CATARINA (CRP/SC). Nota de posicionamento contrário às mudanças na Política Nacional de Saúde Mental propostas pelo Ministério da Saúde. Florianópolis, 14 dez. 2017. Disponível em:

http://www.crpsc.org.br/noticias/nota-de-posicionamento-contr-rio-s-mudan-as-na-poltica-nacional-de-sa-de-mental-propostas-pelo-minist-rio-da-sa-de. Acesso em: 5 jul. 2019.

CONSELHO REGIONAL DE SERVIÇO SOCIAL DO RIO GRANDE DO NORTE (CRESS/RN). Mudanças na Política Nacional de Saúde Mental: mais uma ameaça do governo ilegítimo. Natal, 13 dez. 2017. Disponível: http://www.cressrn.org.br/noticias/ver/1137. Acesso em: 15 jun. 2019.

COSTA, T. C. R. da. A política de saúde mental na contemporaneidade: entre a inovação e o conservadorismo. 2016. Tese (Doutorado em Serviço Social) - Universidade Federal de Pernambuco, Recife, 2016. Disponível em: https://repositorio.ufpe.br/handle/ 123456789/27636. Acesso em: 10 abr. 2019.

COSTA, T. C. R. da. A contrarreforma na saúde e sua expressão na saúde mental: a instrumentalização do direito na saúde mental. In: SILVA, X. A. da.; NÓBREGA, M. B. da.; MATIAS, T. S. C. (Org.). Contrarreforma, intelectuais e serviço social: as inflexões na política de saúde. Campina Grande: EDUEPB, 2017.

DELGADO, P. G. G. et al. Reforma Psiquiátrica e política de saúde mental no Brasil. Conferência Regional de Reforma dos Serviços de Saúde Mental: 15 anos depois de Caracas. 
In: MELLO, M. F., MELLO, A. de A. F. de, KOHN, R. (Org.). Epidemiologia da saúde mental no Brasil. Porto Alegre: Artmed, 2007.

DELGADO, P. G. Reforma Psiquiátrica: estratégias para resistir ao desmonte (Editorial). Revista Trabalho, Educação e Saúde, Rio de Janeiro: Editora Fiocruz, v. 17, n. 2, p. 1-4, 2019. Disponível em: http://www.scielo.br/scielo.php?script=sci arttext\&pid=S198177462019000200200\&lng=pt\&nrm=iso\&tlng=pt. Acesso em: 6 ago. 2019.

DIAS, M. T. G. A reforma psiquiátrica brasileira e os direitos dos portadores de transtorno mental: uma análise a partir do serviço residencial terapêutico Morada São Pedro. 2007. Tese (Doutorado em Serviço Social) - Pontifícia Universidade Católica do Rio Grande do Sul, Porto Alegre, 2007. Disponível em: http://repositorio.pucrs.br Ldspace/bitstream/10923/5102/1/000389624-Texto\%2bCompleto-0.pdf. Acesso em: 1o jul. 2019.

ESQUERDA DIÁRIO. Sobre os avanços de Bolsonaro na contrarreforma da saúde mental e o eletrochoque como norma. Publicado em: 12 fev. 2019. Disponível em: https:// www.esquerdadiario.com.br/Sobre-os-avancos-de-Bolsonaro-na-contrarreforma-da-saudemental-e-o-eletrochoque-como-norma. Acesso em: 28 jul. 2019.

EVANGELISTA, A. P. Interesses privados na Saúde Mental: as contradições que perseguem a efetividade da Política de Saúde Mental no Brasil. Frente Nacional Contra Privatização da Saúde, Rio de Janeiro, 8 dez. 2017. Disponível em: www.contra privatizacao.com.br/2017/12/1123.html. Acesso em: 11 jul. 2019.

GALVANI, G. Bolsonaro tira sociedade civil do Conselho de Políticas sobre Drogas. Publicado em: 22 jul. 2019. Disponível em: https://www.cartacapital.com.br/politica /bolsonaro-tirasociedade-civil-do-conselho-nacional-de-politicas-sobre-drogas/?fbclid =IwAR3Vks7Hp6G2Me8Zs62VpyXOAhsDmYi3KISSRaG7BFsOwNeSWcYZ13R6AU. Acesso em: 28 jul. 2019.

GARCIA, L. et al. Política Nacional de Saúde Mental e organização da Rede de Atenção Psicossocial no Sistema Único de Saúde (SUS). In: BRASIL. Ministério da Justiça, Secretaria Nacional de Políticas Sobre Drogas. Prevenção do Uso de Drogas: capacitação para conselheiros e lideranças comunitárias. 5. ed. Brasília: Senad, 2013.

MOURA, H. C. E. As transformações sócio-históricas da Política de Saúde e de Saúde Mental no Brasil no contexto das Reformas Sanitária e Psiquiátrica. In: TRINDADE, R. L. P. (Org.). Saúde Mental Sociedade: reflexões a partir do Serviço Social. Maceió: Edufal; Imprensa Oficial Graciliano Ramos, 2017.

PEREIRA, L. A. et al. Saúde Mental e Serviço Social: refletindo a prática no contexto neoliberal. In: ENCONTRO LATINO AMERICANO DE INICIAÇÃO CIENTÍFICA. 15, ENCONTRO LATINO-AMERICANO DE PÓS-GRADUAÇÃO, 11., 2006, Vale do Paraíba. Anais... Vale do Paraíba: Univap, 2006. Disponível em: http://www.inicepg.univap. br/cd/INIC 2011/anais/arquivos/0264 0293 01.pdf. Acesso em: 16 jun. 2019. 
PERES, A. C. CapsAD Entrada Livre. Revista Radis, Rio de Janeiro: Editora Fiocruz, n. 202, p. 20-29. 2019.

SAMPAIO, C. Contra retrocessos na política antimanicomial, CNS pede que governo revogue portaria. Brasília, 15 fev. 2018. Disponível em: https://www.brasildefato .com.br/2018/02/15/contra-retrocessos-na-politica-antimanicomial-cns-pede-que-governorevogue-portaria/. Acesso em: 30 jul. 2019.

SANDINI, E. L. L. O ambulatório de Saúde Mental no contexto da Reforma Psiquiátrica: um estudo no município de Taubaté. 2002. Dissertação (Mestrado em Enfermagem) Universidade Estadual de Campinas, Campinas, 2002. Disponível em: http:// repositorio.unicamp.br/jspui/handle/REPOSIP/308778. Acesso em: 12 jun. 2019.

SILVA, A. X. da. Lutas sociais e contradições dos sujeitos políticos coletivos no processo da Reforma Sanitária Brasileira. 2013. Tese (Doutorado em Serviço Social) - Universidade Federal de Pernambuco, Recife, 2013. Disponível em: https://repositorio. ufpe.br/bitstream/123456789/11466/1/TESE ALESSANDRA\%20XIMENES\%20DA\%20SILVA.p df.pdf. Acesso em: 11 jul. 2019.

SILVA, M. F. de A.; MISAILIDIS, M. G. L. M. de. Reflexão sobre ortodoxia econômica e estado de exceção enquanto ameaças aos direitos fundamentais. Revista de Direito, Economia e Desenvolvimento Sustentável, Curitiba, v. 2, n. 2, p. 72-88, 2016. Disponível em: https://www.indexlaw.org/index.php/revistaddsus/article/view/1391. Acesso em: 10 maio 2020.

SOARES, R. C. Governo Temer e contrarreforma na política de saúde: a inviabilização do SUS. Revista Argumentum: Reformas Regressivas e política de saúde, Vitória: UFES, v. 10, n. 1, p. 24-32, 2018. Disponível em: http://periodicos.ufes.br/argumentum/ article/view/19496/13178. Acesso em: 20 abr. 2019.

SOUSA et al. As relações entre público e privado na Política de Saúde Mental e na Política sobre Drogas no Brasil e a particularidade em Alagoas. In: TRINDADE, R. L P. (Org.). Saúde Mental e sociedade: reflexões a partir do serviço social. Maceió: Edufal, 2017.

VASCONCELOS, E. M. (Org.). Saúde Mental e Serviço Social: O desafio da subjetividade e da interdisciplinaridade. 5. ed. São Paulo: Cortez, 2010.

YASUI, S. Rupturas e Encontros: desafios da Reforma Psiquiátrica Brasileira, 2006. Tese (Doutorado em Ciências na área de Saúde.) - Escola Nacional de Saúde Pública da Fundação Oswaldo Cruz, Rio de Janeiro, 2006. Disponível em:

https://www.arca.fiocruz.br/bitstream/icict/4426/2/240.pdf. Acesso em: 20 jun. 2019. 